\title{
DECAY RESISTANCE OF SCOTCH PINE WOOD IMPREGNATED WITH Agaricus campestris BIO-PROTECTIVE EXTRACT
}

\author{
Sibel Yildiz', , Ümit C. Yildiz, ${ }^{1}$ Ayșenur Yilmaz ${ }^{1}$
}

\begin{abstract}
In this study, it was investigated the possibilities of the use of fungal extract as wood protection solution against wood-degrading fungi. For that purpose, the decay resistance of Scotch pine wood samples, impregnated with Agaricus campestris fungal extract, was observed against the brown rot fungus Coniophora puteana. Impregnation procedure was applied at four different concentration levels and with two different extraction methods (hot water and methanol). The concentration levels were arranged as $1 \%, 3 \%, 5 \%, 7 \%$ for hot water and as $1,25 \% ; 3,75 \% ; 6,25 \% ; 8,75 \%$ for methanol. The wood protective efficacy of extract solutions was determined by means of fungi decay test. The mass losses of the samples treated with both fungal extracts ranged from 3,53 to 20,91 . The lowest mass losses in hot water $(4,57 \%)$ and methanol extractions $(3,53 \%)$ were seen in the samples treated at the highest concentration levels ( $7 \%$ and $8,75 \%)$. The wood samples impregnated at $7 \%$ and $8,75 \%$ concentration levels met the requirements of durability class 1 and were classified as very durable. Antifungal activity of methanol extract was stronger than that of the hot water extract. The variations which concentration levels were less than $7 \%$ did not have adequate protection to meet the requirements of the European norms.
\end{abstract}

Keywords: Biodeterioration, bio-protective, Pinus sylvestris, wood decay, wood extracts.

\section{INTRODUCTION}

Wood is an important renewable resources. It has been used as a building material for hundreds of years due to its desirable properties. On the other hand, it is degraded by many organisms (fungi, insect, thermite). Chemical-based preservatives are protect wood from attacks by these organisms (Brown et al. 2001, Nurudeen et al. 2012). But, this type of non-biodegradable chemicals has been limited in many countries, in last years due to their undesirable effects on environment and human health (Pánek et al. 2014). Therefore, latest researches have been focused on finding non-toxic eco-friendly substances obtained from natural and medicinal materials such as plant or fungi (Sen et al. 2009, Nurudeen et al. 2012, Sen et al. 2017, Bahmani and Schmidt 2018).

With the invention and advancement of antibiotics in the early $20^{\text {th }}$ century, many herbicides, insecticides, antibacterial and antifungal agents have been obtained from some important fungal metabolites, and these have been used for plant protection in the agricultural industry (Butt et al. 2001, Yang 2009).

Antimicrobial compounds produced by most fungi can be used as antimicrobial against animal, plant and human diseases. The use of fungicides from fungal metabolites for biological control of tree and plant diseases is a unique approach (Okeke et al. 1992). A study has been performed to extract and describe antibiotics from culture filtrates of some species of Trichoderma for controlling some tree pathogens, including Heterobasidion annosum (Fr.) Bref., a pathogen of pine trees (Dennis and Webster 1971, Yang 2009).

To control various tree diseases, Phaeotheca dimorphospora and its metabolites were used in another study. P. dimorphospora was insulated from elm wood (Desrochers and Ouellette 1994). It was determined that 
this fungus had indicated high antagonistic activity

against several saprophytic and parasitic fungi in softwood and hardwood seedlings, in vitro (Yang et al. 1993). The essential component generated by the fungus was described as salicylic acid (Yang 2009).

Sudirman et al. (1992) also investigated fungal extracts to control white-rot of rubber trees. In the study, the components which have antibiotic effect were extracted from the Lentinus squarrosulus culture medium by butanol. The antifungal activity of the extract was examined against $R$. lignosus. As a result, thermo stability and inhibitory effect was observed.

Fungal extracts can also be used for preveting insects (Yang 2009). In a study, several fungal species were examined for the generation of metabolites toxic to spruce budworm (Choristoneura fumiferana Clemens) larvae (Calhoun et al. 1992). One isolate of Phyllosticta sp. and two isolates of Hormonemadematioides yielded extractable compounds caused the mortality of the insect larvae.

Fungi have long attracted the interest of many industries such as food and biopharmaceutical. They are more well known in terms of their medicinal and nutritional values (Gao et al. 2004, Jo et al. 2014, Wasser 2002). However, many of them have not been yet scientifically tested in terms of their toxic potentials. In this study, the possibilities of using fungal extracts as an alternative wood protection solution against wood-destructive fungi were investigated. For that purpose the antifungal activity of Agaricus campestris (field mushroom), which has been also known as edible species, was examined against the brown rot fungus Coniophora puteana.

\section{MATERIAL AND METHODS}

\section{Wood material}

Scotch pine (Pinus sylvestris L.) wood was obtained from Black Sea Region of Turkey. The sapwood was cut in parallel to grain directions and sawn into specimens measuring 1,5 x 0,5 x 2,5 (tangential x radial $\mathrm{x}$ longitudinal) $\mathrm{cm}$ long. The original sample sizes $(1,5 \times 2,5 \times 5 \mathrm{~cm})$ given in the EN $113(1996)$ test standard have been modified to shorten the test period. All specimens were conditioned at $20 \pm 2{ }^{\circ} \mathrm{C}$ and $65 \pm 3 \%$ relative humidity in the conditioning cabinet until their masses became stable. For each variation ten replicate wood samples were used during impregnation.

\section{Fungus material}

Agaricus campestris, used in the study, was collected from wild areas in Erzurum province located in the east part of Turkey during the month of August in 2016 and brought to laboratory for extraction.

\section{Extractive solutions}

Agaricus campestris fungus samples were dried in an oven at $60^{\circ} \mathrm{C}$ for 24 hours on a food dryer (Profilo, PFD1350W, Turkey) before grinding. A laboratory scale Wiley mill was utilized to grind the coarse particles for the extraction processes. Two different (hot water and methanol) extraction methods were used. The concentration levels of fine wood powders were arranged as $1 \%, 3 \%, 5 \%, 7 \%$ for hot water and as 1,25\%;3,75\%; $6,25 \% ; 8,75 \%$ (by weight) for methanol extractions. Dried and grinded Agaricus campestris powders are shown in Figure 1.

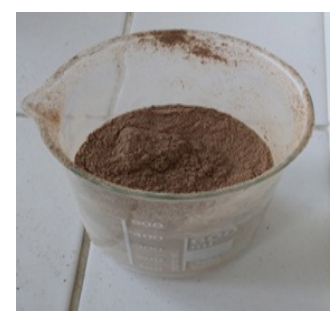

Figure 1: Dried and grinded Agaricus campestris powders. 


\section{Hot water extraction}

Extraction solutions were prepared with distilled water at $1 \%, 3 \%, 5 \%, 7 \%$, (by weight) concentration levels from all fine powders. The prepared solutions were subjected to hot water extraction on a hot plate at 80 ${ }^{\circ} \mathrm{C}$ for a period of 2 hours under continuous stirring with a magnetic stirrer (Figure 2). All extracted solutions were filtrated by Whatman No:4 after cooling for subsequent treatments.

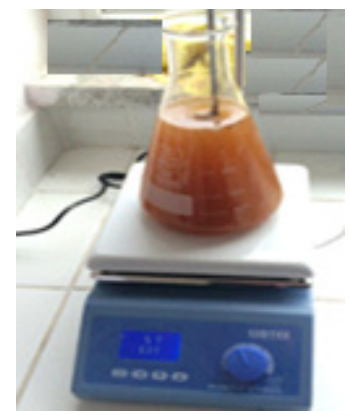

Figure 2: Hot water extraction.

\section{Methanol extraction}

In order to obtain methanol solutions at $1,25 \% ; 3,75 \% ; 6,25 \% ; 8,75 \%$ concentration levels, $2,6,10$ and 14 $\mathrm{g}$ of mushroom powders were placed into a falcon tube. Then, methanol (99\%) was added to the tube and the mixture was stirred continuously with a shaker (HeidolphPromax 2020, Schwabach, Germany) at room temperature for a total of 2 hours. Later particles were removed using filter paper. The difference in concentration between hot water solutions and methanol solutions is due to the specific gravity difference between water and methanol. However, the amount of active chemical substance (mushroom powder) used in each solution is the same. As the basic value that should be taken into consideration here is the amount of active chemical, it can be stated that the small differences between the solution concentrations can be neglected.

\section{Wood impregnation with extracts}

The impregnation procedure was applied according to the ASTM D-1413 1976 standard test method. The whole experiment was performed with ten repetitions. The samples were impregnated in a medium scale impregnation container using a vacuum of $635 \mathrm{~mm}$ of $\mathrm{Hg}$ for $40 \mathrm{~min}$ followed by $15 \mathrm{~min}$ atmospheric pressure. Treated samples were then removed from the treatment solution, wiped lightly to remove solution from the wood surface, and weighed to the nearest $0,01 \mathrm{~g}$ to determine gross retentions. Untreated blocks were used as controls. The retention for each concentration was calculated using the following Equation 1;

$$
\mathrm{R}=(\mathrm{G} \times \mathrm{C} / \mathrm{V}) \times 10
$$

Where:

$\mathbf{R}$ - is the retention $\left(\mathrm{kg} / \mathrm{m}^{3}\right)$

G - mass of the treating solution absorbed by the samples obtained by subtracting the mass of the samples after treatment from the mass of the samples before treatment (gr)

C - the concentration of the treating solution (\%)

$\mathbf{V}$ - volume of the samples in $\left(\mathrm{cm}^{3}\right)$ 


\section{Decay resistance test}

The fungal decay test was done according to the EN 113 (1996) standard test method using a brown rot fungus, Coniophora puteana BAM Ebw. 15. used for both treated and untreated control samples. For each variation it was studied with four test (impregnated) and four control (unimpregnated) samples. Initially, the wood samples were oven-dried at $103 \pm 2{ }^{\circ} \mathrm{C}$ for $24 \mathrm{~h}$ and full dry masses of the samples were determined. They were then placed in a conditioning chamber at a temperature of $20 \pm 2{ }^{\circ} \mathrm{C}$ and a relative humidity of 65 $\pm 2 \%$, for a time to reach the suitable moisture content. Later, the samples were sterilizated in an autoclave at $121 \pm 1{ }^{\circ} \mathrm{C}$ for 20 minutes. The incubation time was approximately 8 weeks at $22 \pm 1{ }^{\circ} \mathrm{C}$ and $70 \pm 2 \%$ relative humidity (Figure 3). Since the sample sizes used in this study were half of the sample sizes specified in the standard, the incubation time was taken as half of the incubation time (8 weeks) indicated in the standard (16 weeks). After the decay test, the wood samples were oven-dried at $103 \pm 1{ }^{\circ} \mathrm{C}$ for $24 \mathrm{~h}$ again to determine mass loss due to fungal attack. The mass loss was calculated as follows (Equation 2):

$$
\text { Mass loss }(\%)=(\mathrm{Mo}-\mathrm{Md} / \mathrm{Mo}) \times 100
$$

Where is the oven dry mass prior to test and is the oven dry mass after the test.

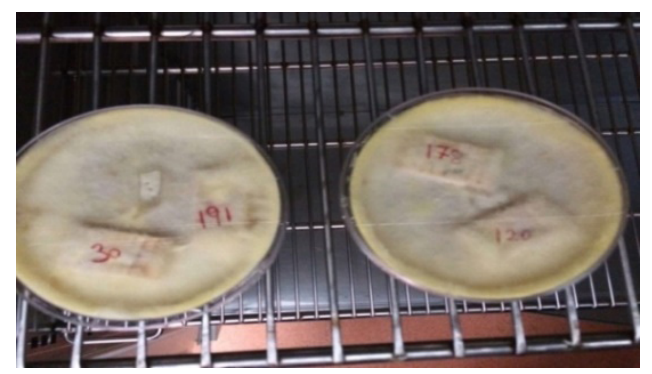

Figure 3: Mycelium growing on the surfaces of petri dish.

\section{RESULT AND DISCUSSION}

\section{Retention}

The average retention of Scotch pine wood samples impregnated with two different extraction solutions were given in Table 1 .

Table 1: The average retention of Scotch pine wood samples $\left(\mathrm{kg} / \mathrm{m}^{3}\right)$.

\begin{tabular}{|c|c|c|c|}
\hline \multicolumn{2}{|c|}{ Hot water extraction } & \multicolumn{2}{c|}{ Methanol Extraction } \\
\hline Concentration (\%) & Retention (kg / m $\left.\mathbf{~}^{3}\right)$ & Concentration (\%) & Retention (kg / m $\mathbf{3})$ \\
\hline 1 & 5,41 & 1,25 & 4,93 \\
& $(0,50)^{*}$ & & $(0,16)$ \\
\hline 3 & 16,72 & 3,75 & 13,40 \\
& $(0,96)$ & & $(0,27)$ \\
\hline 5 & 25,53 & 6,25 & 22,53 \\
& $(1,92)$ & & $(2,11)$ \\
\hline 7 & 36,58 & 8,75 & 34,62 \\
& $(4,23)$ & & $(1,19)$ \\
\hline
\end{tabular}

*: The values in parentheses show the standard deviation. 
It was observed that the retention values increased with increasing the concentration of the fungal extracts, in all variations. The highest retention was seen at the concentrations of $7 \%$ and $8,75 \%$. The retention values obtained from the hot water extraction were found higher than that of the methanol extraction. However there was no observed significant difference in terms of absorption capacity between the hot water and methanol treatments.

\section{Decay resistances}

A criterion of durability classes based on the mass loss according to EN 350-1 (1996) international standard was given in Table 2 . According to the European Standard EN 350-1, the natural durability of wood is described as "the inherent resistance of wood by attack wood destroying organisms" (Van Acker 2003). The mass losses and decay resistance classes of Scotch pine wood samples impregnated with two different extraction solutions were shown in Table 3.

Table 2: Durability classes based on mass loss (\%) according to EN 350-1 (1996) standard.

\begin{tabular}{|c|c|c|}
\hline Durability Class & Description & Mass loss - ML (\%) \\
\hline 1 & Very durable & ML $\leq 5$ \\
\hline 2 & Durable & $5<\mathrm{ML} \leq 10$ \\
\hline 3 & Moderately durable & $10<\mathrm{ML} \leq 20$ \\
\hline 4 & Slightly durable & $20<\mathrm{ML} \leq 30$ \\
\hline 5 & Not durable & ML $>30$ \\
\hline
\end{tabular}

The test results presented in Table 3 revealed that the range of the mass losses of the samples treated with extracts of Agaricus campestris was 3,53 to 20,91. Hot water extract exhibited lower performance than the methanol extract despite the fact that it had higher retention rate (Table 1). Mass losses decreased with increasing the concentration rates. The lowest mass losses $(4,57 \%-3,53 \%)$ were seen in the samples impregnated at the highest concentration levels (7\% and 8,75\%). The greatest mass loss was observed in the control samples (32\%). According to the Table 3, the wood samples impregnated with 7\% and 8,75\% concentrations reached the demand of durability class 1 and were classified as very durable (Table 2).

Table 3: Mass losses and durability classes (DC) of Scotch pine wood samples.

\begin{tabular}{|c|c|c|c|c|c|}
\hline \multicolumn{6}{|c|}{ Mass Losses (\%) } \\
\hline \multicolumn{3}{|c|}{ Water extraction } & \multicolumn{3}{|c|}{ Methanol extraction } \\
\hline $\begin{array}{c}\text { Concentration } \\
(\%)\end{array}$ & Mass losses & $\mathrm{DC}$ & $\begin{array}{c}\text { Concentration } \\
(\%)\end{array}$ & Mass losses & $\mathrm{DC}$ \\
\hline 1 & $\begin{array}{c}20,91 \\
(0,28)^{*}\end{array}$ & IV & 1,25 & $\begin{array}{l}18,34 \\
(0,45)\end{array}$ & III \\
\hline 3 & $\begin{array}{l}15,30 \\
(0,46)\end{array}$ & III & 3,75 & $\begin{array}{l}14,82 \\
(0,85)\end{array}$ & III \\
\hline 5 & $\begin{array}{c}9,43 \\
(0,44)\end{array}$ & II & 6,25 & $\begin{array}{c}7,08 \\
(0,37)\end{array}$ & II \\
\hline 7 & $\begin{array}{c}4,57 \\
(0,17)\end{array}$ & $\mathrm{I}$ & 8,75 & $\begin{array}{c}3,53 \\
(0,19)\end{array}$ & I \\
\hline Control & $\begin{array}{c}32 \\
(1,74)\end{array}$ & V & & $\begin{array}{c}32 \\
(1,74)\end{array}$ & $\mathrm{V}$ \\
\hline
\end{tabular}

*: The values in parentheses show the standard deviation.

The most optimal concentration options were 7\% and 8,75\% compared to other concentrations. At these concentrations the samples reached the demand of durability class 1 and were classified as very durable. The samples impregnated with 5\% and 6,25\% concentrations met the demand of durability class 2 and showed durable performance. The samples treated at $3 \%$ and $3,75 \%$ concentrations met the demand of durability class 3 and were described as moderately durable. These fungal extracts were found biologically active against Coniophora puteana. So, the use of this type of fungal extracts as an antimicrobial agents can be considered as a promising result. In a research it was recorded that some fungal extracts have antibiosis mechanisms that secrete toxic metabolites of the antagonists to other organisms (Yang 2009). P. dimorphospora fungus isolated from elm wood had exhibited strong antagonistic efficacy against many saprophytic and parasitic fungi species 
in hardwood and softwood seedlings in vitro (Yang et al. 1993). The primary functional compound produced by this fungus was described as salicylic acid. Scotch pine wood (control samples) can be considered to be a non-resistant species against Coniophora puteana because the mass loss after of incubation reached 32\%.

As can be seen in Table 3, after the decay test, mass losses occured on both test and control samples exposed to the fungal attack. The mass loss prevention ratio was calculated to emphasize the results of the study more dramatically. This calculation is based on a simple proportional calculation between test and control samples. Mass loss prevention ratios of fungal extracts as compared to the control group were given in Figure 4. The best performance was seen at $7 \%$ and $8,75 \%$ concentration levels in both extraction treatments. The highest mass loss prevention ratios of fungal extracts found in methanol extraction was approximately $89 \%$. The lowest ratio was seen in hot water extraction $(34,65 \%)$ at a concentration of $1 \%$. Antifungal activity of methanol extracts was stronger than that of the hot water extracts. Although the amount of active chemical used is the same, the small difference between the concentrations of water and methanol solutions can be presented as evidence that methanol solutions are more effective. Further, it is also conceivable that the organic solvent methanol can cause the active chemical (mushroom powder) to penetrate the wood tissue better.

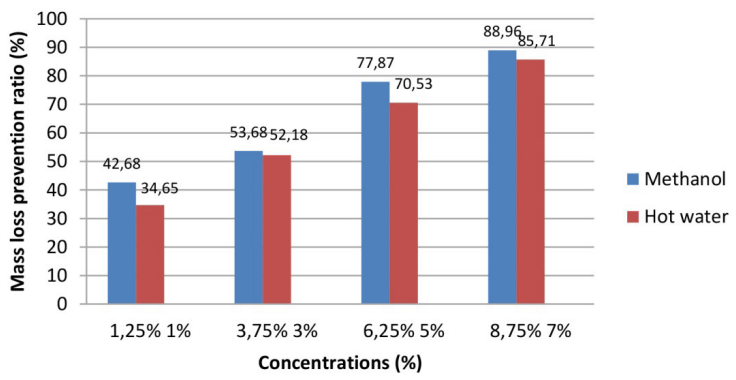

Figure 4: Mass loss prevention ratios of fungal extracts.

It can be considered as an interesting result that an edible mushroom (Agaricuscampestris) has also toxic effect. Jo et al. (2014) recorded that not only toxic mushrooms but also some edible mushroom species can contain poisonous components. Additionally, some procedures during the extraction process may have changed the biological activity of the fungus.

Decay is one of the most important problems restricting the usage of wood and wood based products. In a study about utilization of fungal metabolites conducted by Ricard et al. (1969), it was focused on Scytalidium fungi, which was isolated from a sound Douglas-fir pole. Results showed that the growth of many decay and staining fungi was inhibited. The antifungal compounds produced by Scytalidium were described as "scytalidin" and "scytalidic acid" (Strunz et al. 1972, Overeem and Mackor 1973). These components have been easy to insulate from the metabolites of growing on colonies of Scytalidium. Many decay fungi species were sensitive to scytalidin (Stillwell et al. 1973). Later, Stranks (1976) revealed that the antibiotic scytalidin, generated by Scytalidium isolates, as well as a lot of other antibiotics were capable of inhibiting sap-stain in pine wood. These studies proved the potential utilization of fungal metabolites as wood protectives against some decay and stain (Yang 2009).

In a study, the crude filter-sterilized culture filtrate of Trichoderma (Gliocladium) virens was vacuum impregnated to southern pine wood blocks and then exposed to three brown-rot and white-rot fungi in a soil-block test (Highley 1997). The results demonstrated that the culture filtrate of $T$. virens had fungi static effect against the decay fungi in agar medium, but mass loss of treated wood blocks was slightly decreased. The effective antifungal components generated by the fungus were described as gliotoxin and gliovirin.

In another study, it was observed that some Trichoderma fungi were more efficient against brown-rot fungi, but on the contrary the Aspergillus filtrate was more effective against white-rot Basidiomycetes (Bruce and Highley 1991).

\section{CONCLUSIONS}

In this study, the decay resistance of Scotch pine wood samples, impregnated with Agaricus campestris (field mushroom) fungal extract at different concentration levels $(1 \%, 3 \%, 5 \%, 7 \%$ for hot water and 1,25\%; 
$3,75 \% ; 6,25 \% ; 8,75 \%$ for methanol), was examined against the brown rot fungus "Coniophora puteana". The results indicated that the retention values increased with increasing the concentration levels of the fungal extracts, in all variations. After the decay test, which was performed with modified sample sizes, the mass losses of the samples treated with both fungal extracts ranged from 3,53 to 20,91. Hot water extract was exhibited lower performance than the methanol extract. The lowest mass losses in hot water $(4,57 \%)$ and methanol extraction $(3,53 \%)$ were obtained with the samples impregnated at the highest concentration levels $(7 \%$ and $8,75 \%$ ). The mass loss in the control samples was $32 \%$. The wood samples impregnated at $7 \%$ and $8,75 \%$ concentrations reached the demand of durability class 1 and were classified as very durable. The samples treated with $5 \%$ and $6,25 \%$ concentrations met the demand of durability class 2 and were classified as durable. So, this study demonstrated a high potential for utilization of Agaricus campestris fungal extract for protection of Scotch pine (Pinus sylvestris L.) wood against Coniophora puteana brown rot fungus. However, the variations in which concentration levels were less than $7 \%$ could not have been provided adequate protection to meet the requirements of the European norms (EN 113 (1996)). To further fungus-toxicity against brown rot fungus (Coniophora puteana), the extracts can be mixed with different antifungal materials such as herbal or fungal agents or non-toxic chemicals. Additionally, it can be tried higher concentration levels with more efficient extraction methodologies such as supercritical fluid extraction. But it must not be forgotten that mushrooms consist of $90 \%$ water and especially when studied at high concentrations, there will be needed much more extract. Finally, it can be considered that bio-protection against decay fungi is an applicable prospect. However, there is still need for some basic research in the areas such as optimizing growth conditions of potential bio-protectants and detecting the effect of environmental factors (wood moisture content, temperature).

\section{ACKNOWLEDGEMENTS}

This study was presented firstly as oral presentation at the $48^{\text {th }}$ IRG Annual Meeting in Belgium, 2017.

\section{REFERENCES}

American Society for Testing and Materials. ASTM. 1994. Standard test method for wood preservatives by laboratory soil-block cultures. ASTM D-1413-76. 1994.

Bahmani, M.; Schmidt, O. 2018. Plant essential oils for environment-friendly protection of wood objects against fungi. Maderas-Cienc Tecnol 20(3): 325-332.

Brown, C.J.; Eaton, R.A.; Thorp, C.H. 2001. Effects of chromated copper arsenate (CCA) wood preservative on early fouling community formation. Marine Pollution Bulletin 42(11): 1103-1113.

Bruce, A.; Highley, T.L.1991. Control of growth of wood decay Basidiomycetes by Trichoderma spp. and other potentially antagonistic fungi. Forest Products Journal 41(2): 63-67.

Butt, T.M.; Jackson, C; Magan, N. 2001. Fungi as Biocontrol Agents: Progress, Problem and Potential. CABI Publishing, Wallingford, Oxon, UK. 398pp.

Calhoun, L.A.; Findlay, J.A.; Miller, J.D.; Whitney, N.J. 1992. Metabolites toxic to spruce budworm from balsam fir needle endophytes. Mycological Research 96(4): 281-286.

Dennis, C.; Webster, J. 1971. Antagonistic properties of species-groups of Trichoderma: I. Production of non-volatile antibiotics. Transactions of the British Mycological Society 57(1): 25-39.

Desrochers, P.; Ouellette, G. 1994. Phaeotheca dimorphospora sp. nov.: description et caractéristiques culturales. Canadian Journal of Botany 72(6): 808-817.

European Committee for Standardization. EN. 1996. Durability of wood and wood-based products. Natural durabilityof solid wood. Guide to the principles of testing and classi-fication of natural durability of wood. EN 350-1. 1996.

European Committee For Standardization. EN. 1996. Wood Preservatives. Test Method for Determining the Protective Effectiveness Against Wood Destroying Basidiomycetes. Determination of the Toxic Values. 
EN 113. 1996. Brussells. Belgium.

Gao, Y.; Chan, E.; Zhou, S. 2004. Immunomodulating activities of Ganoderma, a mushroom with medicinal properties. Food Reviews International 20(2): 123-161.

Highley, T.L. 1997. Control of wood decay by Trichoderma (Gliocladium) virens I. Antagonistic properties. Material und Organismen 31(2): 79-90.

Jo, W.S.; Hossain, M.; Park, S.C. 2014. Toxicological profiles of poisonous, edible, and medicinal mushrooms. Mycobiology 42(3): 215-220.

Nurudeen, T.; Abiola, J.; Ekpo, E.; Olasupo, O.; Haastrup, N.; Okunrotifa, A. 2012. Effects of plant extracts as preservative against wood decay fungus Sclerotium rolfsii (Sacc). Journal of Forestry Research and Management 9: 73-82.

Okeke, B.; Steiman, R.; Benoit, J.W. 1992. Production of fungicides from fungal metabolites: a new perspective in the biological control of Pyricularis oryzae. Med Fac Landbouww Univ Gent 57: 403-410.

Overeem, J.; Mackor, A. 1973. Scytalidic acid, a novel compound from Scytalidium species. Recueil des Travaux Chimiques des Pays-Bas 92(3): 349-359.

Pánek, M.; Reinprecht, L.; Hulla, M. 2014. Ten essential oils for beech wood protection-Efficacy against wood-destroying fungi and moulds, and effect on wood discoloration. BioResources 9(3): 5588-5603.

Ricard, J.; Wilson, M.; Bollen, W. 1969. Biological control of decay in Douglas-fir poles. Forest Products Journal 19(8): 41-45.

Sen, S.; Tascioglu, C.; Tirak, K. 2009. Fixation, leachability, and decay resistance of wood treated with some commercial extracts and wood preservative salts. International Biodeterioration \& Biodegradation 63(2): 135-141.

Sen, S.; Yalçin, M.; Tasçioglu, C.; Özbayram, A.K. 2017. Larvicidal activities of some bark and wood extracts against wood-damaging insects. Maderas-Cienc Tecnol 19(3): 273-284.

Stillwell, M.; Wall, R.; Strunz, G. 1973. Production, isolation, and antifungal activity of scytalidin, a metabolite of Scytalidium species. Canadian Journal of Microbiology 19(5): 597-602.

Stranks, D. 1976. Scytalidin, hyalodendrin, cryptosprriopsin--antibiotics for prevention of blue stain in white pine sapwood. Wood Science 9: 110-112.

Strunz, G.; Kakushima, M.; Stillwell, M. 1972. Scytalidin: a new fungitoxic metabolite produced by a Scytalidium species. Journal of the Chemical Society, Perkin Transactions 1 18: 2280-2283.

Sudirman, L.I.; Housseini, A.I.; Le Febvre, G.; Kiffer, E.; Botton, B. 1992. Screening of some basidiomycetes for biocontrol of Rigidoporus lignosus, a parasite of the rubber tree Hevea brasiliensis. Mycological Research 96(8): 621-625.

Van Acker, J.; Stevens, M.; Carey, J.; Sierra-Alvarez, R.; Militz, H.; Le Bayon, I.; Kleist, G.; Peek, R.D. 2003. Biological Durability of Wood in Relation to End-Use, Part 1. Towards A European Standard for Laboratory Testing of the Biological Durability of Wood. Holz als Roh-und Werkstoff 61: 35-45.

Wasser, S. 2002. Medicinal mushrooms as a source of antitumor and immunomodulating polysaccharides. Applied Microbiology and Biotechnology 60(3): 258-274.

Yang, D.Q. 2009. Potential utilization of plant and fungal extracts for wood protection. Forest Products Journal 59(4): 97.

Yang, D.; Plante, F.; Bernier, L.; Piché, Y.; Dessureault, M.; Laflamme, G.; Ouellette, G. 1993. Evaluation of a fungal antagonist, Phaeotheca dimorphospora, for biological control of tree diseases. Canadian Journal of Botany 71(3): 426-433. 